\title{
Dental Patient's Journey Map: Introduction to Patient's Touchpoints
}

\author{
Marina Devetziadou ${ }^{1}$ and Maria Antoniadou ${ }^{2 *}$ \\ ${ }^{1}$ Dentist, Leader at Womentors (cycle of seminars empowering young women) organized by Lamprakis Foundation in collaboration with Active Citizens Fund, \\ Greece
}

${ }^{2}$ Assistant Professor, ACSTH by ICF and AC Accredited Coach, Dental School, National and Kapodistrian University of Athens, Greece

\author{
*Corresponding author: Maria Antoniadou, Assistant Professor, Dental School, Nation- \\ al and Kapodistrian University of Athens, Thivon 2 Str. Goudi, 11527, Athens, Greece. \\ Email: mantonia@dent.uoa.gr
}

Received Date: April 21, 2021

Published Date: May 06, 2021

\begin{abstract}
Introduction: Consumer journey analysis or mapping is an increasingly popular strategic management tool praised by both academics and practitioners for its usefulness in understanding an organization's consumer experience. In the dental sector this could also be a useful tool to enhance the service experience and improve strategic tools of modern dental offices. It seems that as care becomes more patient-centered, care teams need a "single pane" view of the entire dental patient journey.
\end{abstract}

Aim: In this article, we aim to share insights on the importance of mapping out the dental patient's journey to better understand the needs and the impulses that make him choose practitioners and services, and we will mainly focus on identifying dental patients' touchpoints.

Methods: For this article, we gathered articles from PubMed, Google Scholar, Academia, and ResearchGate. We first highlighted consumer engagement for a good branding framework. Secondly, we defined touchpoints' meaning and clarify how they are used today in the world of marketing. Thirdly, we explored the specific engagement behaviors of dental patients according to the relevant touchpoints of a normal dental journey.

Conclusion: Few articles exist on dental touchpoints and branding for dentistry. In the business marketing, there are specific key strategic initiatives at each touchpoint that could be used in the dental field. This initiative can result in a cross functional input aimed to advance dental service innovation with numerous advantages in everyday clinical dentistry. The outcome will be the improvement in the quality of the dental services resulting in a more profitable dental practice.

Keywords: Engagement behaviors; Consumer touchpoints; Customer journey map; Back-of-stage interactions; Touchpoint mapping; Dental branding

\section{Introduction}

Healthcare has recently become a fiercely competitive business endeavor. Until 2010s the health sector was quite isolated from the terms of dental marketing and dental branding. The past couple of years though, researchers focused on redesigning customer experience from the customer's perspective and clearly recognized customer's role in the general business experience. In dentistry, business strategies are usually incorporated a few years later than other fields of human activities. Especially after the burst of COVID-19 pandemic and the sequenced negative economic impacts, improving dental patient's experience is more than just a priority: it is an urgent need. Experienced healthcare providers know that finding, attracting, and retaining new patients has always been a challenging process. Generally, a consumer-patient's experience is not limited to a specific transaction, website visit, or conversation 
with a service representative. It's a process that begins the moment the consumer becomes aware of the company, and it encompasses all the interactions, transactions, and contacts along the way [1], each one of which are mentioned thereafter as patient's touchpoints.

Consumers used to start with a set of potential brands and methodically reduce that number to make a purchase, but today this concept fails to capture all the touch points and key buying factors. The outreach of consumers to marketers has become dramatically more important than marketers' outreach to consumers [2]. This happens because now customers are empowered and wellinformed. A more sophisticated approach is required to help marketers navigate this environment, which is more complicated and it is called the consumer decision journey [2]. This journey is often non-linear, such as someone may jump straight from awareness to purchase if they are not inclined to do research and have a strong recommendation from a friend, for example [2, 3]. The decision-making process is a circular journey with four phases [2]. Although many articles discuss customer journey mapping
(CJM), both academics and practitioners still question the best ways to model the consumer decision journey (CDJ) [4]. This article proposes a solution to the unwieldy complexity of CJM and CDJ in the dental field by enumerating and orchestrating dental touchpoints, which seems to flourish enormous rewards for dental companies and practices.

\section{Definition of Patient's Touchpoints}

A touchpoint is generally any interaction that might alter the way that a consumer feels about a product, brand, business, or service. An example of an encounter with no physical interaction might be discovering an online review. Touchpoints are inseparable elements of creating the overall "patient experience." They lead to patient experience success-long before the patient even meets the provider and long after they have had their first transaction [1, 5] (Figure 1). They can also be intentional (e.g. email) or unintentional (e.g. online review) [1]. Otherwise stated, a touchpoint is any time a potential or real time consumer encounters a brand-before, during, or after the purchase.

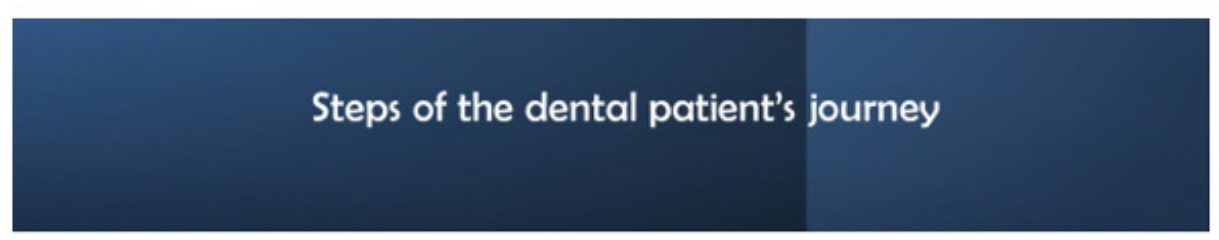

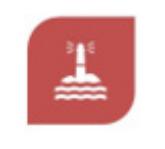

AWARENESS

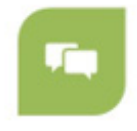

FAMILIARITY

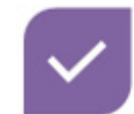

CONSIDERATION

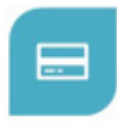

PURCHASE

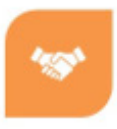

LOYALTY

Figure 1: Steps of previous patients' choices among potential brands.

Additionally, Court, et al. (2009) [2] defined a touchpoint as "an episode of direct or indirect contact with the brand". Thus, touchpoints include but are not limited to channels as defined by Neslin, et al. (2006) [6] as: "a customer contact point, or a medium through which the firm and the customer interact". An expansion of this definition is required for the dental field, as the emphasis in dental interactions commonly excludes one-way communications such as television advertising or direct advertising to local media, while the emphasis on the firm may exclude brand encounters such as "word of mouth" in which the firm is not directly involved [7].

\section{Business touchpoints}

In today's multi-touchpoint, multisensory, multichannel, always-on, hypercompetitive consumer markets, the explosion of potential customer interaction points-across new channels, devices, applications, and more, makes consistency of service and experience across channels, imperative. Recent business practice has also broadly defined the customer experience as "encompassing every aspect of a company's offering-the quality of customer care, of course, but also advertising, packaging, product and service features, ease of use, time-consumed and reliability. It is the internal and subjective response customers have to any direct or indirect contact with a company" [8]. As discussed above, each interaction (touchpoint) creates an opportunity for a moment of truth [1], but often only some of these touchpoints are under the brand's control. These moments of truth are important for the dental office to further evaluate the services if the dentist is of course dedicated to excellence and willing to always provide the best. It is also imperative to notify that touchpoint positivity adds explanatory power to the prediction of change in consideration as compared with touchpoint frequency alone [7].

Furthermore, customer experience is a dynamic process, which incorporates past experiences (including previous "purchases") as 
well as external factors [8]. The truth is that empowered consumers often act more when in an emotional status (for example whether they were in extreme pain on their last endodontic treatment or tooth extraction or the receptionist was quite abrupt on the recall phone-call) than by rationally calculating self-interest [9]. Finally, they take less notice of dental brand's driven communication, choosing instead to learn from the experience of other patients and doing their own research online [7]. When most companies focus on customer experience they think about touchpoints as the individual transactions through which customers interact with parts of the business and its offerings [10]. But this siloed focus on individual touchpoints misses the bigger - and more important - picture: the customer's end-to-end experience [10]. This experience in dentistry is mainly "pain coming-no pain leaving the office" dressed in operational ergonomic and marketing skills. The key solution is always coordinating and integrating the touchpoints so that they seamlessly meld together [11] and rejoice in one united picture: that of an empathic professional with high expertise on the field. Dental touchpoints are bonds created between the patient and the dental brand from direct and indirect ways of information including five senses, written, verbal or non-verbal communication. Analysis of the patient's satisfaction is meanwhile an important component of the ISO $9001 / 2015$ for quality standards in services.

\section{Patient Engagement for A Good Branding Dental Framework}

In the current decade, the major movement in customer management has been on both customer and brand engagement [8]. Patient engagement in the dental industry is the act of building a strong relationship between him and the service provider. It's the sum of all the ways a dental business relates to its patients. It can be through any channel, from in person, to online, to over the phone. The following general definition for customer engagement is reported: "Repeated interactions that strengthen the emotional, psychological or physical investment a customer has in a brand." All those repeated interactions are touchpoints [1]. In other words, touchpoints are brand's points of costumer contact, from start to finish. Consumers interact with service providers through touchpoints, clusters of elements combined into artifacts that foster service experiences. These experiences form a larger arc or path: the customer journey. The series of these experiences aggregate to form an impression of the service in its context; namely, what the customer thinks of the brand. Indeed, this impression (the sum of the experiences) is the brand [9]. Research has suggested that customer experience - in particular, brand experience - is distinct from other brand-focused concepts such as brand involvement and brand attachment [12].

Consequently, dental patient's experience is related to the emerging term of customer engagement and is a multidimensional construct focusing on consumers' cognitive, emotional, behavioral, sensorial, and social responses to a firm's offerings during the entire dental journey. From a customer engagement perspective, customers can also be co-creators of their experience [8]. This is profitable, because it is suggested that patient's assessment of an experience influences key outcomes such as patient satisfaction, patient loyalty, "word of mouth" and patient profitability. For dentists to understand better the patient-customer journey, we provide the example of the usability design strategy for Xerox in the 1980s [13] where the model of the ideal "experience cycle" of the customer was described. The experience cycle model describes the steps people go through in building a relationship with a product or service [9]: -connecting (first impression)-becoming oriented (understanding what's possible)-interacting with the product (direct experience)-extending perception or skill and use (mastery)-telling others (teaching or spreading activation).

According to them, the "experience cycle" plays out at multiple scales [9]. It plays out "in-the-large", across the relationship between a consumer and a product or service. It also plays out "inthe-small", across the consumer's experience with each touchpoint. For example, a good magazine ad connects immediately with readers, presents a clear structure, draws readers in, extends their knowledge, and delights them so much that they show it to other people [9]. A good product package, a good interface, a good support service, and other well-executed touchpoints enable a similar cycle of experience [9].

In dentistry, the "experience cycle" for a dental patient would be: searching for the brand (dental patients google more and decide on word of mouth references [14]) -connecting (first impression of the office, doctor and personnel) - interacting with the service (time consuming, safety issues, economical part of the equitation) - extending perception on doctor skills (specialty, managerial skills, emotional intelligence) - telling others (be a live advertisement of the dentist's work through a nice and healthy smile). The "experience cycle" frames patient- doctor relationship from the patient's point of view and aims to move well beyond a single transaction to foster an on-going collaboration.

\section{Creation of A Dental Patient Journey Map}

Today, more and more dental businesses can capitalize on timely opportunities to optimize their patient journey by outlining key touchpoints on the dental map. In terms of business marketing and simply put, dental patient journey map (DPJM) is an outline of every step patients go through when interacting with a dental professional and there are multiple touchpoints occurring within various stages of this journey. For example, a DPJM timeline includes first engaging with a patient, buying the service, function with a painless mouth and nice smile, sharing about the experience with others, and then finishing the journey by upgrading, replacing, or choosing a competitor. Delivering a distinctive journey experience makes it more likely that patients repeat a service, spend more, recommend to their friends, and stay with the dental firm (Figure 2). So, the first essential step of improving patients' experience is mapping 
out their journey. A patient journey map is a very simple idea: a diagram that illustrates the steps patients go through in engaging with a certain dental brand. These steps, meaning "touchpoints", are typically recorded in chronological order to demonstrate what a typical patient's experience is like with a dental business.

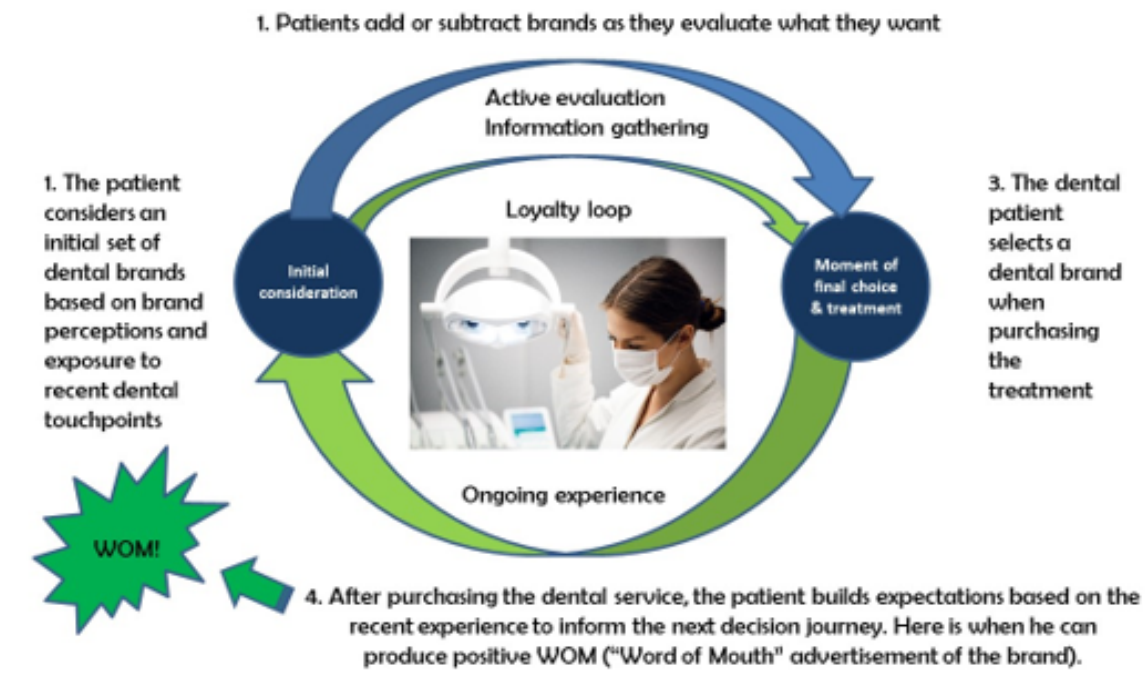

Figure 2: Consumer decision journey.

Grouping specific touchpoints chronologically paints a complete picture of an average patient experience with the dental business and makes it easier for the healthcare team to visualize it. This tactic also improves team members' individual understanding of the patient's needs and expectations as they can pinpoint exactly where their work will influence the patient's journey. With this understanding, dental team can better identify the gaps (touchpoints that cause friction) between its desired and current performance and refocus efforts on new areas of patient experience that could stand improvement. Whether because of poorly aligned incentives, management inattention, or simply human nature, those who manage touchpoints are constantly at risk of losing sight of what the patient sees (and wants)-even as they work hard to optimize their own contributions to the customer-patient experience [10]. Only by looking at the patient's experience through his own eyes, along the entire journey taken, a dentist can create stronger patient experiences and reinforce his engagement. It is also essential to account for both the pre- and post-service aspects of the patient experience. While it may be tempting for a dentist to spend most of his focus on the interactions leading up to the purchase of the dental service, the post-purchase procedure is equally vital to building a complete patient experience.

To maximize customer satisfaction, companies have long emphasized on specific touchpoints. But, doing so can divert attention from the more important issue: the customer's end-toend journey [10]. The goal of every dental office should be creating a positive and consistent experience at all touchpoints and include things that happen before, during, and after the service experience. So, the best choice is to conceptualize patient experience in three overall stages: pre-purchase, purchase, and post-purchase of the service. This tactic makes the process slightly more manageable [15]. There are a few thought-provoking questions which help the dentist divide patients' touchpoints depending on the stage of their cooperation with him that will be discussed further (Table 1).

Table 1: The nine most important questions for determining the stage of cooperation that a dental touchpoint is involved

\begin{tabular}{|l|c|}
\hline 1 & What actions are patients taking to move themselves on to the next stage? \\
\hline 2 & Why are they motivated to keep going to the next stage? \\
\hline 3 & What emotions are they feeling? \\
\hline 4 & Are the dental touchpoints addressing patients' motivations or unmet needs, and answering their questions or allaying concerns? \\
\hline 5 & Are there needs going unstated that neither the dentist nor his competitors are solving? \\
\hline 6 & What are the uncertainties preventing patients from moving on to the next stage? \\
\hline 7 & Are all the touchpoints speaking with the same tone, the same message, even the same words? \\
\hline 9 & Is dental brand being communicated effectively, clearly, and consistently? \\
\hline
\end{tabular}




\section{The First Stage / Pre-Service of the Dental Office}

The pre-service period refers to the customer experience before an actual service begins [4]. In the DPJM process, pre-service experience encompasses all aspects of the patient's interaction with the dental brand before a purchase transaction. Traditional marketing literature has characterized pre-purchase stage as consisting of behaviors such as need, recognition, search, and consideration [8]. To begin with, a dentist should think about all the possible ways patients are aware of his services and his dental brand itself. To achieve this, he should first list the elements of a successful digital marketing content, which are presented in Figure 3. Not surprisingly, health information is the most frequently searched topic online [5] and digital marketing content refers to any material that a company publishes online to promote its brand [16]. So, planning their online presence and reputation as touchpoints, is a powerful tool for dentists to shape expectations and engage new patients.

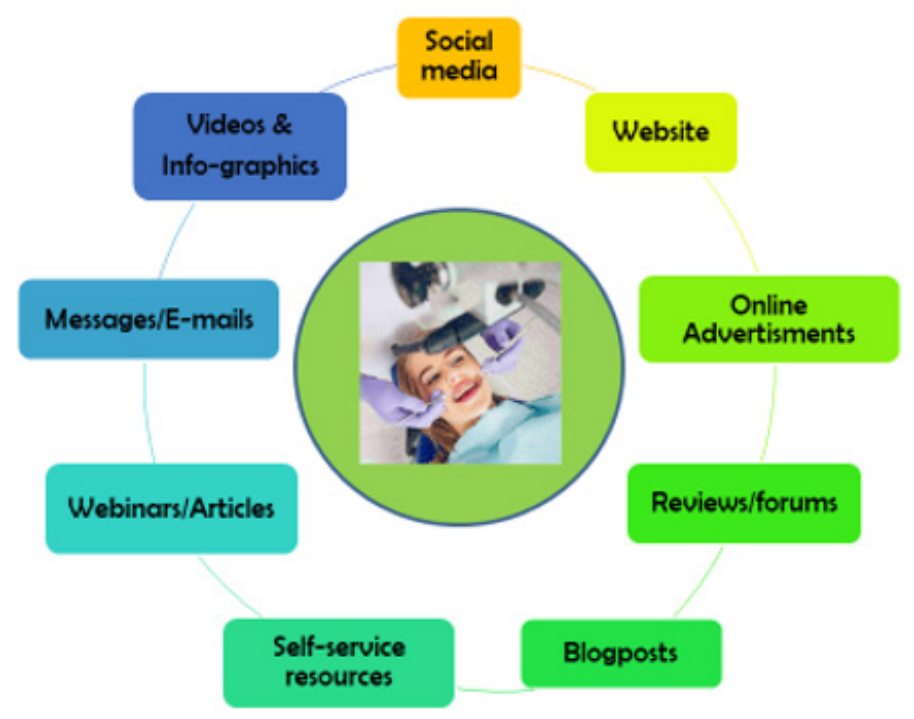

Figure 3: The circle of a successful dental digital marketing.

Social media could be included in every DPJM stage, however, where it's mostly used, is in patient acquisition. That's because social media is a cost-effective way of reaching a large portion of the target audience [16]. Patient-to-patient interactions through social media are creating significant challenges and opportunities for dental professionals [8]. Active social media accounts give dental clinics a face and authentic personality. They are this piece of reputation a dentist can control to gain competitive advantage [14] by promoting his services and enhancing the overall reputation of his brand. Social media except for a great way for the dentist to establish an organic connection with his prospective patients can be also used as an opportunity for patients to get to know him and popularize him in their area [14]. For example, posts with "Before and After" results or dental Q\&As increase credibility and encourage patients to ask for the relevant services. More social media posts examples are described in detail elsewhere [14]. Moreover, it is imperative that these posts are informative and well-written and that the comments of previous patients are positive.

A distinct website is the center of all digital marketing efforts, stands out from competitors' and connects practice with specific new patient demographic target [14]. It is frequently the first interaction a patient has with the practice- "First Visit" page presents dentist's positioning statement that best characterizes the essence of dental practice in the mind of the patient-and first impressions matter. In fact, $48 \%$ of people cited a website's design as the number one factor in deciding the credibility of a business, and once the page loads, users form an opinion in just 0.05 seconds [14]. It seems that a website is critical to the success of the dental practice, but it is useless unless it ranks high in the search results and is highly visible. For example, if national legislation permits the action, banner ads displayed at the top or sidebar of a webpage are touch points that link leads back to website and it's an effective way to draw traffic to a brand's site [16]. Also, social media accounts allow users to interact with its content, such as they can comment, like or share it. This content could refer to dental office's topographic location, different approaching solutions to it, opening/visiting hours schedule, descriptions of dental services which are offered and operating policies (e.g., visits only by appointment).

In today's digital age, customers have smart devices that can call up online reviews about the service, so customer reviews (TripAdvisor, Google) should be positive. Some online retailers include reviews on the listing page, so anyone can see what other customers think without having to navigate away from the page [16]. This consumer-driven type of marketing is increasingly 
important as customers seize control of the process and actively "pull" information helpful to them. Two-thirds of the touch points during the active-evaluation phase involve consumer-driven marketing activities, such as internet reviews and word-of-mouth recommendations, as well as in-store interactions and recollections of past experiences [2]. Patients can access pre-service information not only through social media and website updates, but also through dental blog posts. Blogging frequently and keeping posts focused on oral health, local events and relevant dental issues (e.g., which kind of toothbrush is the best for use), increases familiarity and keeps a concise keyword strategy that further boosts search engine rankings [14]. On the other hand, publishing content with poor grammar or typos, can cause the belief that the dentist is careless and doesn't pay attention to detail.

Other patient touchpoints, apart from an engaging blog post, could be promotional videos and infographics [16]. Healthcare is a prime industry to use videos because of the flexibility of ways in giving information and answering frequent asked questions [14] and the necessity for procedure and treatment overviews to be accessible. Videos can highlight patient reviews and the dental service itself or include an office tour and tooth brushing tips. They offer free engagement in oral health prevention strategies and result in recognition. Infographics based on dental content use striking, engaging visuals (imagery, charts, and minimal text) to communicate information quickly and give an easy-to-understand overview of a topic. Free published articles for local publications or online press releases and webinars could also be included with the first ones increasing dentist's acceptance and recognizability in his area. Online press releases allow newspapers, blogs, or other media sources to see his information and write posts about his office without him needing to put in the effort to connect and claim a story [14]. Webinars, on the other hand, are generally interactive, with participants getting information, asking questions, and discussing in real-time.

Touchpoints need to include every encounter in the attraction process [1], like customer testimonials and whitepapers. Customer testimonials are recommendations from satisfied consumers that affirm the value of a product or service. These are sometimes paid endorsements, as found with influencer marketing or they are given by happy customers, voluntarily, or upon a company's request. A whitepaper is a persuasive, authoritative, in-depth report on a specific topic that presents a problem and provides a solution. Marketers create whitepapers to educate their audience about a particular issue or explain and promote a particular methodology. They're advanced problem-solving guides. Continuing the search of how the service proposition is communicated by the service provider, online self-service resources could be reported (Table 2). When customers are in a hurry or only have a quick question for support team, they don't want to spend 20 minutes waiting on hold for a rep [16]. Instead, a dentist can offer self-service resources which feature troubleshooting steps for them to take on their own and make services seem more approachable.

Table 2: Self-service resources and their positive effects.

\begin{tabular}{|c|c|}
\hline Self-Service Resource & Positive Effect \\
\hline Online scheduling & Time management \\
\hline Customized patient portals & Easy access to health data/Safety of personal rights \\
\hline $\begin{array}{l}\text { Online bill payment and online prescription } \\
\text { renewal }\end{array}$ & Secure payments/Time management \\
\hline Emergency waiting room times & Sense of safety/Quality of care \\
\hline Messaging capabilities & Customized care/Easy access to communication \\
\hline Dentists look up profiles & Sense of familiarity and credibility \\
\hline $\begin{array}{l}\text { Options for virtual visits with health practi- } \\
\text { tioners }\end{array}$ & Sense of convenience and acceptance/ Change of attitude towards oral health for the patient \\
\hline Slide share presentations & Recognition/Quality content driven by patients' wants and needs \\
\hline Reminders about dental service benefits & Full advantage of the benefits of dental insurance or other economical offers \\
\hline Dental app & $\begin{array}{c}\text { Sense of innovation/Time management/ Avoid of annoyance of missed check-ups (e.g., push notifica- } \\
\text { tions) }\end{array}$ \\
\hline
\end{tabular}

Dental patients are interested in many means of comparison, like credentials. These either refer to academic and educational qualifications, such as degrees or diplomas, or occupational qualifications, such as professional certificates and work experience. They could be included in the website content or be shared on Social Media and this makes having followers that are not only other dental professionals, a prerequisite. The prospective patient has been researching healthcare facility, practice and personnel long before the service provider knows about it. More than $80 \%$ of searches begin with a search engine, and three-quarters are via smart phone owners using location-based services [5]. Key local terms can improve website's and general brand's visibility, but it is important that whatever is added to biographies is right and relevant.

Humanizing dental practice and letting patients know about dentist's academic background, training and experience, special skills and specializations, certifications, awards, achievements, along 
with community involvement improves the sense of familiarity and safety [14]. Being an active member of the society in the area that a dentist serves, creates opportunities for partnerships and group actions. For example, connection with local and regional dental associations or active participation in community organizations, local government, and education programs globally, or locally, make the impression of an approachable, trustworthy and high-quality individual, characterized by consistency, responsibility and social interest.

To further discuss the pre-service stage, patient onboarding is the process of welcoming new patients, getting them registered into the practice's system, and orienting them with how things work. As such, it provides the first impression of the dental facility and sets the tone for the patient's experience. Pre-appointment packets are a good example. Everything from the format, directions, and apparent redundancies provides an opportunity to improve patient engagement [17]. The question is: "Do new patients fill the entire packet of past medical history, procedures, surgeries, etc. in advance of their appointment, or do they spend the first 15 minutes of an initial appointment in this paperwork?" Submitting earlier this packet electronically to the clinic, gives the clinician the required time to review it before patients arrive and greatly improves experience for both. It's a win-win. But if professionals are not careful, their on-boarding process can turn an opportunity to impress into a liability for complaints and frustration [17].

On the phone interactions are also crucial. To be successful, telephone as a touchpoint needs to be staffed by a well-trained and experienced person [5], such as it is the first point of human contact and the basis for initial rapport and trust [5]. A significant amount of new business is won or lost when the phone rings in the dental office. The difference between success and failure is in recognizing that the prospective patient's initial call is full of uncertainty [5] The office person should listen carefully, understand caller's need and reassure that a near-term appointment with a service provider of the facility is the proper decision. Between the initial phone conversation and the initial office appointment, it is usually helpful to continue the rapport building with a comforting contact [5]. Some people may prefer an email while others may prefer a voice mail message or phone follow-up. For example, elderly people are not familiar with technology and prefer to use telephone communication. So, the best thing to do is ask patient's preference. Without being intrusive, this touchpoint is personal assurance, from the office to the individual that reduces anxiety and builds the relationship [5].

E-mails and messages are one-way communications that include brand, collateral, manuals, advertising [11] and trial offers. A trial offer in the dentistry field is an opportunity to buy or use a service free or at a reduced price for a particular period to encourage patients to visit dental practice. Email automation could be also used for sending appointment and "It's Time For..." reminders, requesting a friend referral and giving patients motivation to keep up with their dental health [14]. Finally, an opt-in email list allows customers to sign up to receive email correspondence and alongside allows a dentist to connect with potential and current clients [14].

Touchpoints go beyond the brand advertising, which is generally referred to as paid media, to include traditional earned media such as editorial coverage [7] and peer-to-peer encounters with the brand such as word-of-mouth (WOM) conversation. Traditional marketing remains important, but the change in the way consumers make decisions means that marketers learn to influence consumer-driven touch points, such as word-ofmouth and Internet information sites [2]. WOM is defined as any conversation (whether online or offline) with other individuals in which the brand is mentioned [7].

The more patients see, hear and feel about a name; hopefully the more they will associate and accept its messages in the long term [14]. People trust recommendations from friends more than any other form of advertising, but it's not a close race. 83\% of customers say that their friends and family are their most trusted sources of referrals [16]. This makes it imperative for businesses to focus on word-of-mouth marketing if they want to be trustworthy [16]. It is also remarkable that findings, based principally on analysis of 54 interviews over 3 years, show that organizations devote considerably more attention, energy and resources to the management of negative WOM than they do to the promotion of positive word-of-mouth $[18,19]$. NWOM is regarded as a significant threat to revenues, customer loyalty, customer acquisition, brand equity, organizational reputation, employees' morale, and management tenure [18].

WOM marketing agencies such as Buzzador, Social Soup and TRND offer brand owners the prospect of their marketing message reaching vast numbers of potential customers through the offline and online communication activities of campaign participants [20]. Research has shown that these messages spread not only from campaign participants to their immediate friends and family, but also continue to spread more widely into social networks [20]. Also, $50 \%$ of all campaign-related conversations are conducted as institutional talk and 50\% are embedded in everyday chitchat [21]. Additionally, it is noted that a small number of highly influential people can influence the beliefs, attitudes and behaviours of hundreds, perhaps thousands of others [22]. From a business perspective, these Influencers, sometimes known as opinion leaders, can be identified, reached and persuaded to exert their influence. The difficulty and high cost of identifying Influencers [22] led Mancusoto successfully test the idea that it might be more "fruitful to focus attention on the potential of creating opinion leaders" [23].

As noted already effective communication of the brand message at every marketing opportunity, such as direct mail newsletters, postcards, and brochures represents a great amount of patients touchpoints. But professionals shouldn't ignore that the visual 
identity of a brand is a touchpoint itself. Visual identity should be clear, uncluttered and unique to brand's identity, because it is competing with 3,000 commercial messages that prospective patients are exposed per day [14]. For example, people judge a brand's name according to visual attractiveness of its letters, words and symbols [24]. Additionally, a physical store-office includes touchpoints like signage [4] to guide people. As a result, dentists could catch patients' attention with three-dimensional billboard designs and moving parts (e.g., shopping bag or pen with service's logo). A catchy logo, a colourful poster by the entrance of the office or at the front page of the website can encourage the sense of sight to dominate over all other senses in patients' decision-making process.

The accessibility of dental office is also one of the most critical factors for patients to choose a dental practice. It is beneficial for dental office to be supported by public transportation system and include information of location on its contact pages. Google map \& local directions not only encourages visitors to choose a dentist's practice, but it also quickly boosts his local SEO score [14]. Local landmarks like hospitals or schools and local keywords result in convenience and time management especially for newcomers in the neighborhood or city. Finally, local business listings are online portfolios that contain information about a business, such as name, address, phone number and hours of operation. These are some of the most popular items on social media, since they represent a huge amount of all posts shared and they don't need to be only about dentistry.

\section{The Second Stage/Current Service}

The service period refers to touchpoints that patients experience during an actual service [4], as it covers all customer interactions with the brand and its environment during the purchase event itself [8]. It is characterized by behaviors such as choice, ordering, and payment [8]. Dental touchpoints during this phase include patients using the parking lot and discovering in-office incentives and special prices. A clean, safe, well-lit parking lot or a dental office that is designed to be accessible for patients with disabilities make a good first impression. As for incentives, from a customer perspective they increase the perceived value of a purchase and from a business perspective they help brands establish goodwill an incentive doesn't have to be a tangible good, it can be anything that encourages a customer to take action (like discounts, "freebies," or other courtesies [5]). Offering for example free Wi-Fi throughout the dental office encourages patients' communication and real-time promotions with social media.

As referred, visualization is used as an effective strategy before a patient makes the decision to visit the dental office in the first place [24] and the physical office can also be a make-it or breakit first impression [5]. Initially, the signage which guides patients' arrival at the dental office is important because sight, is a sense that dominates over the other four [24]. An office environment that does not appear to be clean, modern, up-to-date, or warm and welcoming will have an immediate negative impact [5]. So, the best way to take advantage of sight is by shape and by the interior design of dental office. Seating areas should be clean and mall interiors need to be bright, attractive, aesthetically pleasing, and comfortable. Also, material and texture of the furniture plays a key role, and the color and logo of the brand can be inflicted on the uniform of the staff for an organized branding effort.

Another way to take advantage of sight is the promotion of the practice on a waiting room TV [14]. It gives the impression of a modern, progressive-minded, and inviting dental practice. Patients appreciate being entertained and having something to watch during their exam or while waiting in the lobby. The lobby is like the front of a house and patients want to feel comfortable and at home waiting for their treatment. Most video/photos on TV should be things to ease their mind. Effective examples are testimonials, segments explaining the benefits of dental service or showing the newest technology ("What makes dental practice unique?"), meet the team videos and community service work photos. Dentists can also explain a current promotion they run or promote an upcoming event they are hosting. Continuing, smell is the sense with the greatest emotional and sensitive impact and in-service industries, scents could become assets in brand differentiation that can trigger memories of pleasant emotions. Ambient scenting provides a positive effect on patient perceptions of the quality of service they are receiving, the cleanliness of the office, as well as the overall personal wellness [24]. In an environment, such as a dental office where emotions like anxiety dominate, enjoyable fragrances have anxiolytic effects, reduce the unpleasant emotions of a delayed or canceled appointment and introduce the sense of familiarity.

It is evident that auditory stimuli, such as music, slogans, voices, words or familiar noises that are associated with the business, touch an individual at a deeper emotional level than tactile stimuli [24]. A successful auditory sensory strategy improves patients' overall satisfaction. As sound influences the customer's choice of brand it is very easy and affordable to add sound quality in the dental services [24]. Relaxing music suits to the brand value and essence, reduces patient's anxiety and his perception of luxury services provision. In addition, the front desk is a hub for patient touch points, such as front office staff is usually the first people from the clinic patients speak with and they're also generally the last [17]. That's why it's so important to hire the right people, train them appropriately, and work to build a patient-centric culture in the dental clinic. One of the many front desk touchpoints is the check-in process. Patients welcoming and providing them with clear and understandable directions is one part of this process and proving a minimum wait time is the other.

A pooled model suggests that positivity of in-store (and in this case in-office) communication is in general more influential than that of other touchpoints including brand advertising [7]. For example, human contact, such as a firm handshake [24] or a mat with a warm welcome signage, can do wonders to the experience 
and expectations of a patient in the dental office. A greeter who welcomes patients directly, addresses them by name, helps them with initial sign-in and points to comfort points such as free WiFi and office conveniences, "consists" the main part of an effective informational desk. Attractive help desks could also encourage patients to provide the dental branding efforts with feedback. On the other hand, extended waits that often accompany many service encounters can put people in a bad mood, tempers can flare and disruptive behavior can result [25]. Failing to manage customer lines can be a serious oversight, according to Raymond, et al. [25]. Communicating with current patients can be difficult, especially when instances like cancellations, emergencies, or clinic closures occur with little notice [17]. Great service comes by forming personal, emotional connections with the customers [11]. Even if wait times are on the longer side, how this is communicated to the patients by front desk staff can make all the difference between a good experience, and a complaint [17].

Any in-person interactions either with company representatives or other patients, can be considered significant touchpoints. An almost entirely neglected touchpoint, peer observation, is both pervasive and persuasive [7]. Peers may exert influence, solicited or unsolicited, in all three stages of the experience [8] and inoffice conversations are the most direct points of contact that have an immediate impact on the customer's purchase decision [16]. Observing peers may impact service satisfaction [25]; the similarity of others may increase purchase intentions [26]; and consumers who purchase products with the support of others, may form more enduring brand relationships [7,12]. However, a brand is about managing how patients feel when they are both in direct and indirect contact with the dental practice. Customer Relationship Management (CRM) is a cost/ profit issue, and it is generally believed to cost more to gain a new customer than it does to retain an existing one [27].

An effective CRM strategy includes:

a) strategy development (choice of target segments, tiering of service, and design of loyalty rewards)

b) value creation (delivering benefits to customers through tiered services and loyalty programs)

c) multichannel integration to provide a unified customer interface across many different service delivery channels [28].

Research also identified consistent and clear communications as one of the most important elements of customer experience [10]. A well thought out communication strategy that engages patients and makes them feel of being part of something significant, is the solution. Basic characteristics of this strategy are analyzed in (Table $3)$. In general, the manner and method in which we communicate with patients opens the door for outstanding experiences [17]. Given the advancement in technology, when selecting which method, the clinic uses to communicate with patients, dentist should take into consideration patient demographics, desires, and values. For example, if most of his patients are elderly, do not like using computers, and value personal interaction, then maybe moving all patient communications to a cloud-based secure messaging system isn't the way to go [17]. Though, not only the method of communication sends subtle cues that can impact the patient experience, but also the style or manner. This applies to clinic communications like call-backs or scheduling and it also applies to in-person communication as discussed above. The way a dentist says things to his patients matters almost as much, if not more, than what he says.

A strong example is that when a dentist says to his patient: "I know this pain feels real to you."; what the patient hears is: "but it's not real for me." Saying things like this to patients automatically undermines the therapeutic relationship [17]. Every dental clinic should value one-on-one care and work to make sure every patient receives individual attention from clinicians. But, this will fall on deaf ears if those statements aren't backed up in practice [24], such as the individual experiences that people have with the service provider are the ones that define patients' perception of the practice. Services themselves are individual touchpoints and every dentist should promote his professional skills efficiently. The main characteristic of a true professional is empathy, the ability to sense other people's emotions. Patients can tell the difference between a clinic that is really trying to provide great individualized care and one that is just saying what it must as an excuse for wait times or other inefficiencies [17]. For example, free sharing of knowledge through emotional connection and free services for the underprivileged [14] results in cooperation through values, integrity and humanism and endears the practice to like-minded individuals (Table 3).

Table 3: Characteristics of an effective communication strategy.

\begin{tabular}{|c|c|}
\hline Communication Touchpoints & Achievements \\
\hline Focusing on practice's goals and benefits & Loyalty/Patients feeling valued and cared for \\
\hline Telling the truth about the practice & Clear communication and trust \\
\hline Being ready to provide answers in the question: “Why to choose you?” & Creation of a storytelling brand/Enhancement of the personal brand \\
\hline Not building brand's reputation on one person's name & Patient's comfort and trust towards each member of the dental team equally \\
\hline $\begin{array}{c}\text { Adopting a blended model for communicating with patients (e.g., offer- } \\
\text { ing patients a choice about how they receive communication) }\end{array}$ & $\begin{array}{c}\text { Making patients feel heard/Improving their experience by participating in } \\
\text { the patient-clinic relationship }\end{array}$ \\
\hline Using an understandable, clear and accurate way of communication & $\begin{array}{c}\text { Reduction of conflict and misunderstandings/Ease of communication, phys- } \\
\text { ical and virtual }\end{array}$ \\
\hline
\end{tabular}




\begin{tabular}{|c|c|}
\hline Using emotional language/Showing empathy & $\begin{array}{c}\text { Elicitation in patients of the emotional outcome dentist wants (e.g., feeling } \\
\text { empowered, inspired or motivated) }\end{array}$ \\
\hline $\begin{array}{c}\text { Effective structuring of communication } \\
\text { experience }\end{array}$ & Getting the information across/Engaging patients and improving their \\
\hline $\begin{array}{c}\text { Training of employees on service quality, active listening, problem reso- } \\
\text { lution, and dental office's policies }\end{array}$ & Enhancement and consistency of the brand image and brand message \\
\hline $\begin{array}{c}\text { Not setting expectations outside the scope of the primary purpose or } \\
\text { capabilities }\end{array}$ & Avoiding patient's discomfort, mistrust and disappointment \\
\hline
\end{tabular}

Continuing, as healthcare changes, more and more patients are becoming aware of the costs associated with dental treatment and questioning whether receiving treatment is worth the cost. The best way to address this concern, while also building trust with patients, is to be as open and up-front about the costs of treatment [17]. For some clinics who have moved to a cash-based model, conversations about cost and expenses are becoming easier [17]. Point of Sale is the last touchpoint patients will reach before making a purchase of a dental service. In other words, it is the specific point in time when a financial transaction takes place. In this point in time, patients realize exactly why they need the product or service. For many businesses, this is a momentous step in the customer journey [16]. Nothing can turn a good experience sour quite as fast as a patient being told that they owe much more than they anticipated for their visit [17]. A solution might be scheduling an appointment with a patient, then calling the patients back a few days before their appointment and informing them of the costs. Taking this extra step lets patients know that dental clinic truly cares about their cost of attending treatment. Going a step further, dentists should be able to have discussions with patients about length of treatment programs and how that affects the cost. These conversations make patients feel valued and cared for.

This stage will end up with incorporating in the process the so called "trouble tickets" (TT). TT teams could be typically small groups of practitioners, dental associations or other individuals like Coaches or Mentors who are able to develop, deploy and maintain large-scale systems to keep modern dental businesses assessed and eligible for running. They record important information on trouble tickets and use them for communication between the patient and the dental brand to improve services. These tickets can be printed or emailed or messaged forms on the informational desk or through phone applications that give the opportunity to every patient or employee that has a problem, to submit the relevant document, or ticket, to a TT team describing their issue. Marketing practice in all industries is being revolutionized by the application of TT to support new structures, strategies and relationships [29]. TT teams will be possibly the next decade forms of assessment and quality control assurance of the dental practices needed in a dental brand environment locally or nationally.

\section{The Third Stage/Post-Service}

The post-service period refers to the customer experience following the actual purchase and encompasses customer interactions with the brand and its environment. This stage includes behaviors such as usage and consumption, post-purchase engagement, and service requests [8]. Dental touchpoints that transpire after a patient leaves the dental office may include a patient recommending it, talking to others about it or even planning a return in the very near future. It is a fact that people refer more often and more passionately to a brand they like, trust and has these characteristics $[14,24]$. To achieve this, a dentist could launch online initiatives that encouraged patients to spread positive word of mouth feedback or share experiences and recommendations on the brand's interactive blog and in its online patient forum. Creating a universal brand which appeals to many patients improves mouth to mouth marketing. Another way to encourage patients' word-ofmouth communication is to design a screening area that features the mall's name, website name, and interactive background. This office's display allows patients to share activity information via social media and post pictures of themselves enjoying their dental service experience. It also gives patients an incentive to use dental brand's hash-tag.

Patient feedback builds stronger relationships, enhances trust and moves the practice to excellence [14]. Despite low customer satisfaction and thus low levels of positive customer WOM, other organisation-influenced practices such as referral programs can be deployed to produce positive WOM [19]. So, a dentist can engage patients through his retention process, such as a referral program or feedback surveys. A referral program is a growth marketing tactic that seeks to encourage existing customers to recommend a brand to their friends, family and colleague. Feedback surveys are sent after a purchase and they evaluate the customer's experience with the service [16]. If the customer leaves a negative review, the company can reach out to learn more about the issue [16]. Except for customer feedback surveys, there are customer success programs which have a variety of touch points found within them. When customer success recognizes a potential problem, they reach out to customers to notify them of the issue or offer a solution [16]. This demonstrates a commitment to the customer's goals which builds additional rapport over time [16].

In addition, a dentist can build patients' rapport by following up with a" thank you letter" or a gift. This letter can be an email, or, if possible, a hand-written note and the gift might be offering a free service to the next appointment. It's a great way to develop a long-term relationship with patients [16]. There are plenty choices of free customer Thank You Letter templates on the internet. The dental team needs to be creative and resourceful on this matter. 
Customer loyalty programs are another important touchpoint that service teams should be aware of [16]. Loyalty programs are ubiquitous, and firms lure consumers with rewards in exchange for loyalty so that they can retain and increase their market share [30]. These programs strengthen the patient-dentist relationship by turning them into lifelong advocates. If consumers value rewards, any competitor offering a no-rewards deal would face a competitive disadvantage [30]. By incentivizing people with exclusive rewards and discounts, not only businesses develop customer loyalty but also provide crucial information on how customers are spending and what types of offers are most appealing.

Subscription renewal is the process each customer goes through when continuing his subscription into the next billing cycle. If a business is subscription-based, renewals are crucial to its revenue model, as they maintain steady growth. Subscription-based dentistry allows private dental offices to create a packaged plan of preventive care and offer it to uninsured patients at an affordable price point [31]. It is important that the dentist removes as much friction as possible from his renewal process. After all, it should be effortless for an existing patient/customer to stay a customer after their contract is up [16]. Generally, by appealing to five senses, dental brands aim to create strong memories in patients' mind [24] and even stronger bonds between patients and brands. The more a patient involves with the sense, the more he will be able to remember the brand [24]. Being able to obtain memories (good ones) during their dental services experiences is crucial for patients because they need reasons to return in a particular dental office repeatedly. Patients individually access the service by comparing service expectations with their personal experiences.

It was reported that prior experience influences current satisfaction, which in turn influences future usage [32]. Past experiences - at each stage of the customer's experience may influence his or her current experience [8]. Key patient touchpoints are patients' previous visits to the dental office and with similar service providers in the past. For example, the characteristic smell of eugenol, which typically clings to dental offices, may contribute to their apprehension by eliciting memories of previous unpleasant dental care experiences, involving painful restorative dentistry on vital teeth [24]. Continuing with post-service touchpoints, reminding patients brand's existence is imperative. Every dentist should be knowledgeable on internet technology, such as planning for example email and mobile application strategies [4], allows patients to receive real-time updates and reminders. Another example is customer support channels, which are any platforms that service agents use to communicate with customers [16] and include chat, email, phone, social media and peer review sites.

Also, up-selling and cross-selling emails customize what a dentist is selling based on his patients' needs. A great way to cross sell is to offer services that complement each other. A dental visit with a thorough work or sending a reminder of an event can be used as an example. While addressing patient Mary: "Mary your veneers look fabulous! To protect your investment most of our patients get an occlusal guard after getting veneers. Let's take that impression today. "By using the word "majority" it makes it feel less of a sales pitch.

A billing action is often an overlooked touchpoint on this list. That's because it happens after a purchase occurs and has no direct influence on the customer's decision process. However, it's still a vital step in the customer's journey because a negative experience can result in an immediate instance of churn, if not addressed properly.

To sum up, the most important part of the third stage is the answer to this question: "How does the service provider follow up with customers?" A strong recall system that includes powerful touchpoints is the answer. When patients' recall is predetermined in time, they feel safe and confident for the duration of therapeutic effect. Also, a follow-up call to patients that underwent extensive therapy treatments makes a good impression.

Significant managerial research has extended this after-service process to include the "loyalty loop" as part of the overall customer decision journey [2] (Figure 2), suggesting that during the postpurchase stage, a trigger may occur that either leads to customerpatient loyalty (through repurchase and further engagement) or begins the process anew, with the patient reentering the prepurchase phase and considering alternatives [8].

\section{Dental patients' touchpoints from another per- spective.}

In the previous section, we focused on how dental patients interact with multiple touch points, moving from consideration, search, and purchase to post-purchase, consumption, and future engagement or repurchase. The goal of this analysis was to describe patients' journey and understand the myriad possibilities and paths, they may take in multiple purchase phases. But, recently, DPJM has begun to include the role of partners, past experiences and external influences. One article defines a customer experience ecosystem as "the complex set of relationships among a company's employees, partners and customers that determines the quality of all customer interactions" [8]. Ultimately, a touchpoint is any time a potential patient encounters the dental brand before, during, or after the purchase of the services offered. Based on the above restrictions, researchers identified four categories of customer experience touchpoints, which we have adjusted in the dental practice environment. These four are brand-owned, partner/ employee-owned, patient/customer-owned and social/external/ independent touchpoints.

Though, sometimes the line between brand-owned and partner-owned touchpoints may blur and partners or external factors may also influence some brand-owned touch points [8]. For example, sometimes sources like Social Media or Review sites can be considered independent; sometimes they are more closely 
aligned with the brand; and sometimes they may be considered partner touchpoints. For this reason, researchers have made the distinction between firm-initiated and customer-initiated touch points; in this case, brand-owned and partner-owned touch points would be more firm-initiated, whereas the customer-owned and social/external touch points would be more customer-initiated [8]. The categorization of patients' touchpoints as brand-owned, dental team-owned, patient-owned, and social/external is described in Table 4.

Table 4: Patients' touchpoints categorization influenced by brand, dental team, patient and social elements.

\begin{tabular}{|c|c|c|c|}
\hline Categories of brand & Social Media & Advertising & Website \\
\hline \multirow{12}{*}{ Brand-owned } & Blogs & Dental App & Loyalty programs \\
\hline & Front desk & Effective communication strategy & Search engine management [3] \\
\hline & Email appointment verification & Subscription renewals & $\begin{array}{l}\text { Specified information technology, tools } \\
\text { and materials }\end{array}$ \\
\hline & Environmental stimuli of dental office & Service quality of design & Online reviews \\
\hline & Company events & Published articles & Ample parking spaces \\
\hline & $\begin{array}{l}\text { Clean sitting areas and office interior } \\
\text { design }\end{array}$ & $\begin{array}{l}\text { Free Wi-Fi throughout the dental } \\
\text { office }\end{array}$ & “Thank you” letters \\
\hline & Testimonial opportunities [17] & Online physician/facility ratings & Consistency across all platforms \\
\hline & Videos & Infographics & Webinars \\
\hline & Initial follow -up & First impression of the dental office & On phone interactions/ Mobile channels \\
\hline & Self-service resources & Credentials & Recall system \\
\hline & Visual identity of the brand & Location of the dental office & Incentives/Special prizes/Gifts \\
\hline & Interior design & Ambient- relaxing scenting & Auditory stimuli (e.g., classical music) \\
\hline \multirow{11}{*}{ Dental team-owned } & In-office communications & Front-facing patient interactions & On phone interactions \\
\hline & Communication channel partners & Loyalty programs & Back-office internal processes \\
\hline & $\begin{array}{l}\text { Service delivery process and service } \\
\text { design }\end{array}$ & $\begin{array}{l}\text { Specified training, licenses and certi- } \\
\text { fication }\end{array}$ & Active listening and problem resolution \\
\hline & $\begin{array}{l}\text { Active work with community organisa- } \\
\text { tions }\end{array}$ & Billing actions & Self-Service resources \\
\hline & Insurance verification and referrals & $\begin{array}{l}\text { On boarding process of new patients/ } \\
\text { Check-in process }\end{array}$ & Recall system \\
\hline & First impression of dental staff & Credentials & Local connections \\
\hline & Up-selling/ & Incentives/Special prizes & Patients welcoming \\
\hline & Cross-selling emails & & \\
\hline & Trouble tickets [1] & $\begin{array}{l}\text { Free sharing of knowledge with } \\
\text { patients }\end{array}$ & Free services for the underprivileged \\
\hline & Dental services & Costs of treatment & Referral programs \\
\hline & Customer success programs & Customer support channels & Application strategies \\
\hline \multirow{3}{*}{ Patient-owned } & $\begin{array}{l}\text { Patients' thinking of their needs and } \\
\text { desires }\end{array}$ & Instructional videos on YouTube & Patient posting a picture and reviews \\
\hline & "Word-of-mouth" & Financial obligations and expectations & Customer reviews \\
\hline & Whitepapers & Customer testimonials & Point of sale \\
\hline \multirow{4}{*}{$\begin{array}{l}\text { External/Indepen- } \\
\text { dent }\end{array}$} & Other customers & Peer influences & $\begin{array}{l}\text { Third party information sources (e.g., } \\
\text { review sites and Social Media) }\end{array}$ \\
\hline & $\begin{array}{l}\text { State of economy (on a macro level) and } \\
\text { economic situation of patients }\end{array}$ & $\begin{array}{l}\text { External environments (e.g., Poor } \\
\text { weather on the day of the appoint- } \\
\text { ment) }\end{array}$ & Past traumatic dental experiences \\
\hline & Social environment & Extreme crisis like Covid-19 crisis & Competitor actions \\
\hline & Location of the dental office & Internal events (e.g., service crises) & $\begin{array}{c}\text { Customer's dynamic external environ- } \\
\text { ment }\end{array}$ \\
\hline
\end{tabular}

\section{Discussion}

The service encounter has been defined as "a period of time during which a consumer directly interacts with a service" [33].
However, when one thinks of service encounters, what commonly comes to mind is interpersonal exchange between customers and service providers $[33,34]$. These interpersonal exchanges can 
strongly influence customers' satisfaction with service organisations [25]. Service encounter is often a complex phenomenon that may comprise a wide array of elements [35]. Separately or collectively, these myriad elements found may affect the quality of customerservice provider interaction and, ultimately, the customers' service experiences [25]. One such element is the presence of others in the service environment [34, 36, 37].

By proactively providing chances for in-office relationships to develop, dentists can cultivate a brand community and thereby increase patients' loyalty. Community-integrated customers serve as brand-missionaries, carrying the marketing message into other communities [38], such as they are emotionally invested in the welfare of the company and desire to contribute to its success. Though, the intangible nature of services (like medical, dental or insurance services) makes them difficult for customers to evaluate prior to purchase [39]. The heterogeneity of labor-intensive services encourages customer loyalty when excellent service is experienced [39]. The object of improving service quality, after all, is to engender customer loyalty. Satisfaction is one of several antecedents of loyalty [27] and as seen above, there appears to be a clear relationship between customer satisfaction and word-ofmouth.

Relationship marketing is a new-old concept [39]. Formally marketing to existing customers to secure their loyalty was neither a top priority of most businesses nor a research interest of marketing academics [39]. As Schneider wrote in 1980, [40]: "What is surprising is that researchers and businessmen have concentrated far more on how to attract consumers to products and services than on how to retain those customers".

Although relationship marketing terminology in the services literature can be traced back to 1983, when Berry [41] outlined five strategy elements for practicing relationship marketing, it wasn't until today that relationship marketing and touchpoints' strategy are at the forefront of marketing practice and academic marketing research. Also, many researchers and consultants including Morris, et al. (1999) claimed that intimacy, trust and commitment are the cornerstones of customer loyalty [27] and Geller (1997) identified 14 elements important in achieving customer loyalty [42]. The most significant of which are the quality/value of the product and service, the impression or image portrayed, the dynamism of the organisation, communication and achieving the unexpected for customers [42].

Relationship marketing benefits the customer as well as the firm [39]. Medical, banking, insurance, and hairstyling services illustrate some or all of the significant characteristics (importance, variability, complexity, and involvement), that would cause many customers to desire continuity with the same provider, a proactive service attitude, and customized service delivery [39]. Relationship marketers have attempted to bond customers to their companies in several ways [43]. Social, technological, legal, economic and cultural bonds all serve as exit barriers, discouraging customers from seeking alternative suppliers [29]. A key influence on loyalty is the offer of unique value delivering advantages not provided by competitors [27]. Customers are only loyal if it benefits them.

Common benefits customers see include:

a) feeling that there is less risk of something going wrong, ability to trust the provider, and receipt of the firm's highest level of service,

b) being known by name, friendship with the service provider, and enjoyment of certain social aspects of the relationship,

c) special treatment benefits, including better prices, extra services, and higher priority [28].

Furthermore, the results of an exploratory principal components factor analysis suggest that consumers perceive that brands have five distinct personality dimensions: Sincerity, Excitement, Competence, Sophistication, and Ruggedness [44]. Brand personality is defined formally as "the set of human characteristics associated with the brand" [44]. Consumers easily can think about brands as if they were celebrities or famous historical figures [45] and as they relate to one's own self [46]. That we are what we have is perhaps the most basic and powerful fact of consumer behavior [47]. A successful brand has the capacity of making consumers feel like they are part of it or even that they "own" it. So, a branded practice will be worth more than a non-branded practice, because it causes the target market to think that they have developed their perception of the brand all by themselves [13].

There are many points along a dental patient journey and engagement process that can either add to or detract from a patient's total experience in a clinic or facility [17]. Taking the time and effort to look touchpoints not just as isolated mini-experiences, but as a collective whole [11], will help the dentist shape them for a better patient experience, and even point to opportunities to invent new types of touchpoints. A dentist might always deliver a great service, on time, with a smile, but a wayward touchpoint like offtarget advertising or an unwieldy website can scare patients off. Fortunately, most of these touchpoints are within brand's control and as referred priorly most brand-owned touchpoints can be regarded as dentist-owned ones. All a dentist should do is identify them and start getting feedback. Also, being creative (grouping them in a timeline for example) with how he thinks about the touchpoints along the journey can yield surprising benefits.

However, not all "touches" are equal: Some interactions matter more than others [1], such as there are so many ways for consumers to experience a brand. Apparently, satisfying all customers with the same service delivery is virtually impossible [25]. As the old phrase states, "one man's ceiling is another man's floor". Therefore, dentists should understand how each touchpoint contributes to the overall patient experience and take notes while he is in his patient mindset. Managing the customer base via service tiering, which divides the 
customer base into different value tiers (e.g., platinum, gold, iron, and lead), helps to tailor strategies to the different service tiers [28]. The higher tiers offer higher value for the firm, but also expect higher service levels [28]. In other words, clinicians shouldn't design all-inclusive patient journey maps that contain all possible touchpoints, as doing so can result in a highly complex map that patients may or may not follow. On the other hand, after identifying all of them they should focus on the most critical ones and on the ones that fit better to each patient.

For a dentist, knowing his touchpoints and realizing their significance is only half the battle. To improve patient satisfaction, he needs to make sure each touchpoint leads to a good customer experience and delivers on customers' expectations. Expectations (including beliefs, evaluative criteria, attitudes, and activity sequences) often hide emotional outcomes. Emotions are subjective, fluctuating across individuals and social situations, which makes them challenging for consumers to predict [48]. Efficient touchpoints make the new patient increasingly confident and familiar with the provider's office. As questions of uncertainty are gradually removed, the patient's fears or anxiety are replaced by a positive patient experience [5]. The feelings of the unknown become awareness of capability, service and confidence in the provider, staff and office as a rich and personal resource [5].

To see what's working, a professional can run customer feedback surveys at each major touchpoint or set up customer experience management software. But he should make sure not lose sight of the big picture and always look at the entire journey. When he walks himself through the patient's journey step-by-step, all the pieces should become clear. He could also accomplish this task by directly asking patients to walk him through their experience with his brand, as it is more manageable by stepping out of dentist's role and into the patient's shoes. DPJM should diagram what customers really do, instead of what managers imagine they do [4]. So, it is crucial for dentists to ask patients map out their journeys for them by using customer self-journey mapping or develop ideal customer journeys. Dentists should also ensure to consider a range of perspectives from internal stakeholders. Insights into the journey are embedded across every part of the company so it is important to include opinions from all of team members. The acceleration of technology advancement means more options become available with increasing regularity. So, except for being based on personal opinions (patients or dental team members), journey mapping should be more data based, taking advantage of new technologies such as Wi-Fi-based location services.

Attempting to measure the patient experience with a single metric can be an overly simplistic and risky approach. Patient experience management requires a multidisciplinary approach in which multiple functions (i.e., marketing, operations, customer service, human resources) cooperate to deliver a customer experience and firms require specific capabilities (e.g., partner network management, customer analytics) to develop successful customer experience strategies [8]. For many companies, combining operational, marketing, customer and competitive-research data to understand journeys is a first-time undertaking, and it can be a long process-sometimes lasting several months [10]. But the reward is well worth it; creating a fact base allows management to clearly see the customer's experience and decide which aspects to prioritize [10]. The final step in the Wheel of Loyalty (WL) is to understand what causes customers to leave and then systematically reduce these churn drivers [28]. Common causes for customers to switch include core service failures and dissatisfaction, perceptions that pricing is deceptive and unfair, inconvenience, and poor response to service failures [28].

In conclusion, dental industry is dramatically changing due to the rapid rise of consumerism in healthcare together with the COVID-19 recession crisis in healthcare systems worldwide. The role of dentists in this unprecedented era, is to put patients' needs first and provide them with high quality dental care. It is on the patient's mindset and psychology that the dentists should focus on them instead of focusing on the competition. All the information above gives the dentist a deep understanding of what today's patients want from an optimum dental health care facility and the knowledge that patients' touchpoints play key role along the dental journey. A successful dental practice of the after Covid-19 era should be "branded" by his choices, his actions and his earned reputation.

\section{Conclusion}

- A dental touchpoint is any area that the dentist, his clinic, or dental staff interact with a patient or potential patient. From the first phone call to the last treatment; from the first advertisement to the last piece of communication, these interactions make up the patient experience.

- Grouping dental touchpoints chronologically helps marketing and patient-customer service teams identify touchpoints that cause friction so they can remove them and enhance the dental patient journey (DPJ) within the office.

- $\quad$ Dentists, in the after-Covid era, striving to improve patient satisfaction, they should have their patients in mind at every touchpoint, to achieve their goals.

- Many dental touchpoints take place in multiple purchase stages (pre-service, during service and post-service stage).

- The dental patient journey analysis should understand and map touchpoints from the patient's perspective and, therefore, requires their input.

- $\quad$ To build a useful dental patient journey map, dentists need to gather patients' information, identify both critical and less important touchpoints and ensure that each one leads to positive experiences. 
- A great part of touchpoints is within dental brand's control and are characterized as brand owned. By this sense, DPJs are repeatable and can be repeated for a meaningful percentage of patients.

- An established dental relationship, along with good service and measurable results, typically leads a patient to recommend and refer. Word-of-mouth (WOM) begins as testimonial opportunities, online physician/facility ratings, and positive social media comments and postings.

- In the future, the role of the dental patient should be extended more because patients can be co-creators of value, independently or jointly with the dental brands.

\section{Acknowledgement}

None.

\section{Conflict of Interest}

The authors declare no conflict of interest.

\section{References}

1. Patterson (2018) How to Measure Touchpoint Effectiveness: Six Steps to Better Customer Experiences, Marketing Profs.

2. Court, Elzinga, Mulder, Vetvik (2009) The consumer decision journey, McKinsey Quaterly.

3. Richardson (2010) Using Customer Journey Maps to Improve Customer Experience. Harvard Business Review.

4. Rosenbaum, Otalora and Ramírez (2017) How to create a realistic customer journey map. Business Horizons 60(1): 143-150.

5. Gaughran (2017) 4 Patient Experience Touchpoints: Doing the Right Thing. PatientExperience.com.

6. Neslin (2006) Challenges and Opportunities in Multichannel Customer Management. Journal of Service Research 9(2): 95-112.

7. Baxendale, Macdonald and Wilson (2015) The Impact of Different Touchpoints on Brand Consideration. Journal of Retailing 91(2): 235253.

8. Lemon and Verhoef (2016) Understanding Customer Experience throughout the Customer Journey. Journal of Marketing: AMA/MSI Special Issue 80: 69-96.

9. Dubberly and Evenson (2008) The experience cycle. ACM Interactions, Volume XV.3.

10. Maechler, Neher and Park (2016) From touchpoints to journeys: Seeing the world as customers do. Copyright (C) 2016 McKinsey \& Company, p: $1-10$.

11. Richardson (2010) Touchpoints Bring the Customer Experience to Life. Harvard Business review.

12. Schmitt, Brakus (2009) Brand experience: What Is It? How Is It Measured? Does It Affect Loyalty? Journal of Marketing 73: 52-68.

13. Rheinfrank, Hartman and Wasserman (1992) Design for usability: crafting a strategy for the design of a new generation of Xerox copiers Usability: turning technologies into tools. Oxford University Press, Inc, USA, p: 15-40.

14. Devetziadou and Antoniadou (2020) Branding in dentistry: A historical and modern approach to a new trend. GSC Advanced Research and Reviews 3(3): 51-68.

15. Schmitt (2003) Customer Experience Management: A Revolutionary Approach to Connecting with Your Customer. New York: John Wiley \& Sons.
16. Fontanella (2020) 20 Customer Touchpoints That Will Optimize Your Customer Journey. HubSpot.

17. Salazar (2018) How to Improve Patient Experience: Touch Points. Rehab Solutions.

18. Williams and Buttle (2014) Managing negative word-of-mouth: an exploratory study. Journal of Marketing Management 00: 1-25.

19. Williams and Buttle (2011) The Eight Pillars of WOM management: Lessons from a multiple case study. Australasian Marketing Journal 19: 85-92.

20. Groeger and Buttle (2014) Word-of-mouth marketing influence on offline and online communications: Evidence from case study research. Journal of Marketing Communications 20(1-2): 21-41.

21. Groeger and Buttle (2015) How everyday conversation promotes WOMmarketing campaign reach: a mixed methods investigation. Advertising, Promotion and Marketing Communications, EMAC Conference, pp: 1-7.

22. Groeger and Buttle (2012) Influencers and their circle of friends: enriching social network analysis with qualitative data. Australia: MGSM, Macquarie University, pp: 1-7

23. Mancuso (1969) Why Not Create Opinion Leaders for New Product Introductions? Research Article 33(3): 20-25

24. Antoniadou and Devetziadou (2020) Sensory Branding: A New Era in Dentistry. On J Dent \& Oral Health 3(4).

25. Grove and Fisk (1997) The impact of other customers on service experiences: A critical incident examination of "getting along". Journal of Retailing 73: 63-85

26. Thakor (2008) Effects of service setting and other consumers' age on the service perceptions of young consumers. Journal of Retailing 84(2): 137-149.

27. Buttle and Burton (2002) Does service failure influence customer loyalty? Journal of Consumer Behaviour 1(3): 217-227.

28. Lovelock and Wirtz (2008) Services marketing ( $7^{\text {th }}$ edn,): People, Technology, Strategy. Part IV, Chapter 12: 314-348.

29. Buttle (1996) Relationship marketing: Theory and Practice. Manchester Business School, UK, pp: 1-55.

30. Duque (2017) The Costs of Loyalty. On Loyalty Rewards and Consumer Welfare. Economic Analysis of Law Review, EALR 8(2): 411-450.

31. Wells (2018) Subscription-based dentistry: The solution dentistry desperately needs. DE Dental Economics.

32. Bolton and Lemon (1999) A dynamic model of customers' usage of services: Usage as an antecedent and consequence of satisfaction. Journal of Marketing Research 36(2): 171-186.

33. Shostack (1985) Planning the Service Encounter, In John A Czepiel, Michael R Solomon, Carol F Surprenant (Eds.) The Service Encounter. Lexington, MA: Lexington Books, Pp: 243-254.

34. Lovelock (1996) Services Marketing, ( $3^{\text {rd }}$ edn.), Englewood Cliffs, NJ: Prentice-Hall.

35. Shostack (1987) Service Positioning Through Structural Change. Journal of Marketing 51: 34-43.

36. Baker (1987) The Role of the Environment in Marketing Services: The Consumer Perspective, In John A Czepiel, Carole A Congram, James Shanahan (Eds.), The Service Challenge: Integrating for Competitive Advantage. Chicago: American Marketing Association, pp: 79-84.

37. Martin and Pranter (1989) Compatibility Management: Customer-toCustomer Relationships in Service Environments. Journal of Services Marketing 3: 6-15.

38. McAlexander, Schouten and Koenig (2002) Building Brand Community. Journal of Marketing 66(1): 38-54.

39. Berry (1995) Relationship Marketing of Services: Growing Interest, Emerging Perspectives. Journal of the Academy of Marketing Science 23(4): 236-245. 
40. Schneider (1980) The Service Organization: Climate is Crucial. Organizational Dynamics pp: 52-65.

41. Berry (1983) Relationship Marketing. In Leonard L Berry, G Lynn Shostack, Gregory Upah (Eds.) Emerging Perspectives on Services Marketing. Chicago: American Marketing Association, pp: 25-28.

42. Geller (1997) Thank you so much for your recent purchase...Customer Retention Begins with the Basics. Direct Marketing 60(5): 58-63.

43. Storbacka (1994) The Nature of Customer Relationship Profitability. Helsinki: Swedish School of Economics and Business Administration.

44. Aaker (1997) Dimensions of Brand Personality. Journal of Marketing Research 35: 347-356.
45. Rook (1985) The Ritual Dimension of Consumer Behavior. Journal of Consumer Research 12: 251-64.

46. Fournier (1994) A Consumer-Brand Relationship Framework for Strategy Brand Management. Unpublished doctoral dissertation, University of Florida, USA.

47. Belk (1988) Possessions and the Extended Self. Journal of Consumer Research 15: 139-168.

48. Arnould and Price (1993) River Magic: Extraordinary Experience and the Extended Service Encounter. Journal of Consumer Research 20: 2445 . 